\title{
ABO,RH, KELL and MN systems within Uterine Cancer
}

I. Nakashidze ${ }^{1}$, N. Kotrikadze ${ }^{2}$, M. Nagervadze ${ }^{1}$, L. Ramishvili², M. Alibegashvili², N. Petrovic ${ }^{3}$, N. Kedelidze ${ }^{1}$, S. Garakanidze ${ }^{1}$, B. Sepiashvilli², K. Dolidze ${ }^{1}$, R.

Khukhunaishvili', M. Koridze', D. Baratashvili', S. Ahmad ${ }^{4}$.

${ }^{1}$ Batumi Shota Rustaveli State University, Department of Biology, Batumi, Georgia.

${ }^{2}$ Ivane Javakhishvili Tbilisi State University, Department of Biology, Tbilisi, Georgia.

${ }^{3}$ Vinca Institute of Nuclear Sciences University of Belgrade, Department for Radiobiology and Molecular Genetics, Belgrade, Serbia.

${ }^{4}$ Florida Hospital Cancer Institute, Department of Gynecologic Oncology, Orlando-FL, USA

Objectives: The blood group antigens are found in several human cell types. There is a variable expression of histo-blood groups antigens within normal endometrium, which are also involved in hormonal regulation of glycosyltransferase activity. We aimed to investigate $\mathrm{ABO}, \mathrm{RH}-\mathrm{hR}, \mathrm{Kel}$ and $\mathrm{MN}$ systems in women with Uterine cancer (UCa) in Adjara (Georgia) population.

Methods: Internationally recognized immunoserology methods were used to reveal the erythrocyte group antigens. The obtained results were statistically processed by using appropriate formulas.

Results: From $\mathrm{ABO}$ system alleles, $r$ and $q$ alleles frequencies were higher within the patients with UCa compared with control group of patients. From $\mathrm{Rh}-\mathrm{Hr}$ system, the distribution frequencies of $\mathrm{D}, \mathrm{c}$ and e alleles, $\mathrm{Cc}$, Ee and EE genotypes, $\mathrm{cDe}, \mathrm{cDE}$ haplotypes are increased in UCa. From Kell $\mathrm{q}(\mathrm{k})$ and $\mathrm{p}(\mathrm{K})$ alleles, $\mathrm{p}(\mathrm{k})$ allele tends towards to $\mathrm{UCa}$ in the tumor. Notably, MN system $p(M)$ and $q(N)$ alleles, revealed $q(N)$ allele increased frequency in UCa compared to control group.

Conclusions: Based on our study, ABO, RH-hR, Kell and MN systems antigens may be may be useful for UCa predisposition and and development.

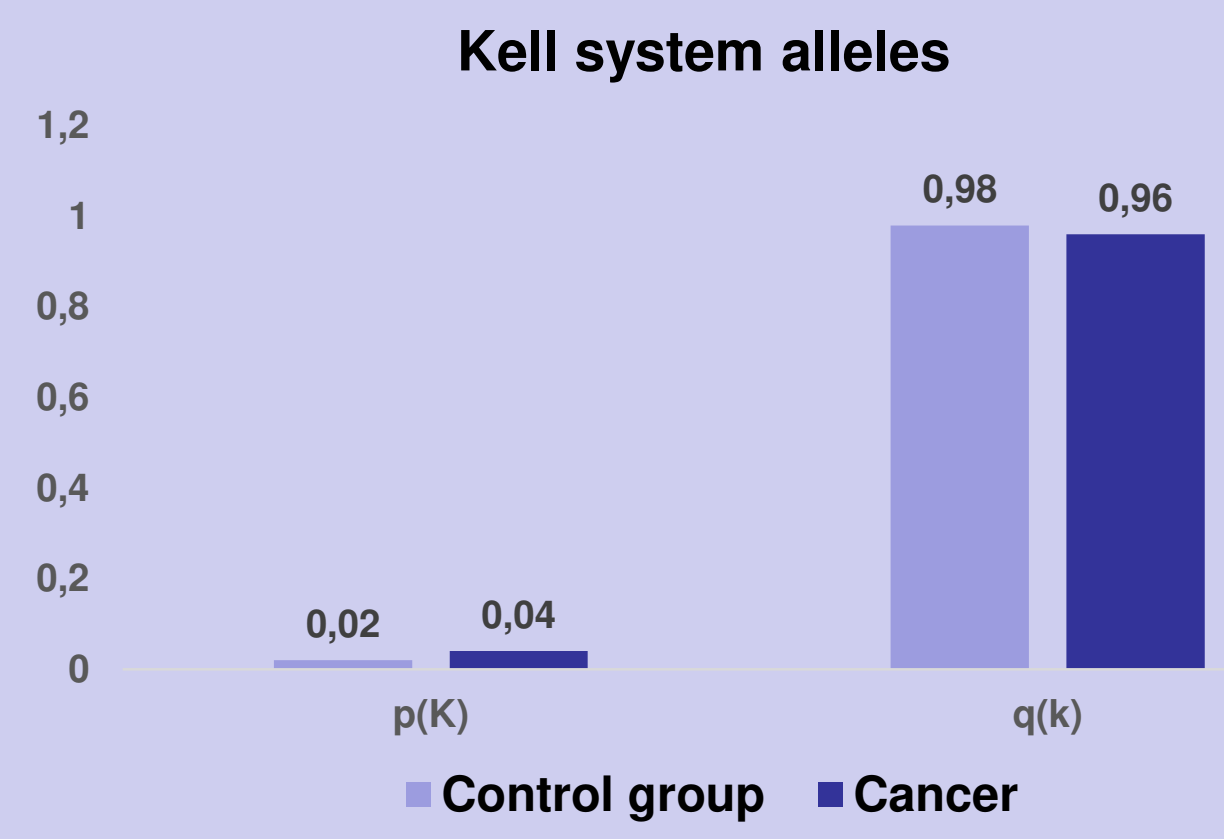

\section{Table 1. RH system Alleles in Uterine cancer}

\begin{tabular}{|r|c|c|}
\hline $\begin{array}{c}\text { Rh-Hr } \\
\text { System Alleles }\end{array}$ & $\begin{array}{c}\text { Control group } \\
(\mathbf{n}=\mathbf{1 3 0 )}\end{array}$ & $\begin{array}{c}\text { Uterine Cancer } \\
(\mathbf{n}=\mathbf{1 1 5})\end{array}$ \\
\hline $\mathrm{D}$ & 0.6 & 0.67 \\
\hline $\mathrm{C}$ & 0.42 & 0.27 \\
\hline $\mathrm{C}$ & 0.72 & 0.82 \\
\hline $\mathrm{E}$ & 0.22 & 0.17 \\
\hline $\mathrm{C}$ & 0.7 & 0.8 \\
\hline
\end{tabular}

Table 2. RH system Genotypes in Uterine cancer

\begin{tabular}{|c|c|c|}
\hline $\begin{array}{c}\mathbf{R h}-\mathrm{Hr} \\
\text { system genetics } \\
\text { variants }\end{array}$ & $\begin{array}{c}\text { Control group } \\
(\mathbf{n = 1 3 0 )}\end{array}$ & $\begin{array}{c}\text { Uterine Cancer } \\
\mathbf{( n = 1 1 5 )}\end{array}$ \\
\hline CC & $9.23 \pm 2.5 \%$ & $3.47 \pm 1.7 \%$ \\
\hline Cc & $46.15 \pm 4.3 \%$ & $37.39 \pm 4.51 \%$ \\
\hline cc & $44.61 \pm 4.3 \%$ & $53.9 \pm 4.46 \%$ \\
\hline EE & $0.76 \pm 0.7 \%$ & $4.34 \pm 1.9 \%$ \\
\hline Ee & $17.69 \pm 3.3 \%$ & $20.86 \pm 3.78 \%$ \\
\hline ee & $81.54 \pm 3.4 \%$ & $74.78 \pm 4.04 \%$ \\
\hline
\end{tabular}

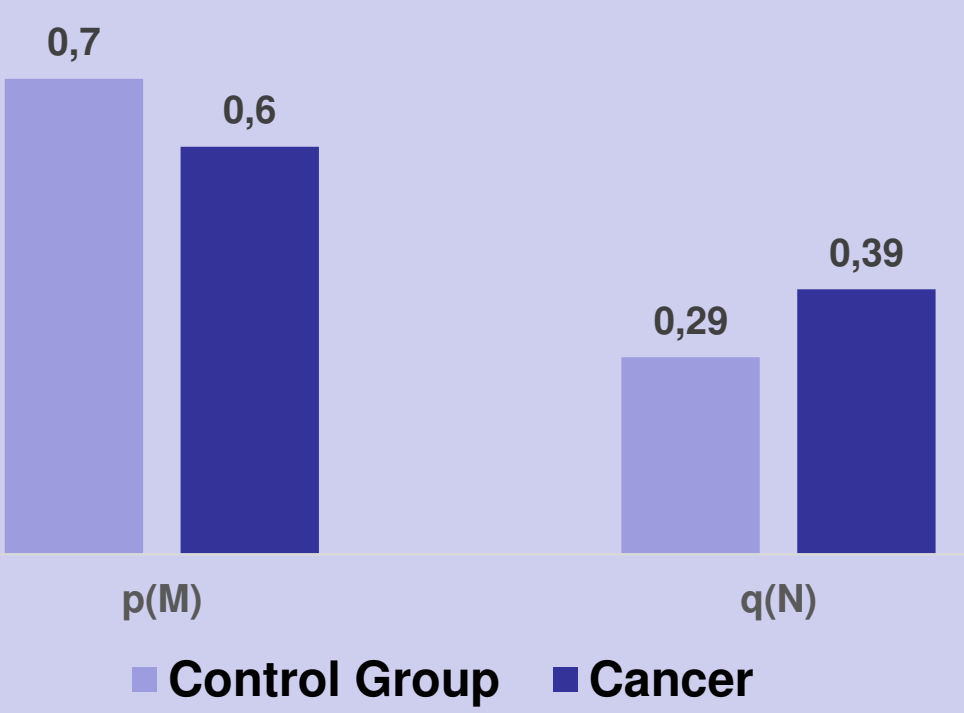

